Yuned, Thematic Progressions Of The 2015 Telfin...

\title{
THEMATIC PROGRESSIONS OF THE 2015 TEFLIN ARTICLE ABSTRACTS IN APPLIED LINGUISTICS
}

\author{
Reski Oktaviani Yuned \\ Azwandi \\ Arono \\ University of Bengkulu \\ Email : reski.oktaviani@gmail.com
}

\begin{abstract}
Coherence is one of the characteristic of good academic writing, including abstract that represent the whole content of research article in order to be able to show what messages want to be expressed in the abstract. This study investigated the English abstract TEFLIN in applied linguistisc written by Indonesian speaker in its coherence by analyzing the theme and rheme. This study focuses on (1) identifying the theme which are dominantly used in 2015 TEFLIN article abstracts written by non-native speaker of English (2) identifying thematic progressions which are dominantly used in 2015 TEFLIN article abstracts written by non-native speaker of English (3) finding out coherences' quality of the research article abstract section in 2105 TEFLIN article abstracts in applied linguistic based on thematic progression. This study was designed by using descriptive qualitative. The results show that the type of theme dominantly used in 2015 TEFLIN article abstracts written by non-native speaker of English is topical theme, not all non-native speakers of English use textual theme, and just a few of them use interpersonal theme. In addition, Zig Zag pattern in thematic progression is dominantly used then followed by reitaration theme, and the last Multiple (Split) pattern, none of the abstracts use Derived TP pattern. Most of the research article abstract section in TEFLIN abstracts in applied linguistic have fair quality, just a few included to less quality, none of them was catagorized as good and poor quality. It can be concluded that English abstracts of TEFLIN in applied linguistisc written by Indonesian speakers can be catagorized as good abstract based on their coherence.
\end{abstract}

Keywords: Abstract, Coherence, Theme, Thematic Progression.

\section{INTRODUCTION}

Abstract is one of the important parts or sections of an academic writing due to the fact that it is a kind of short condensed text to represent the whole text or overview of a research article it is located in the first section of research article. This is the point that determines whether readers will continue to read the next section or not. It is important for the researcher to write the abstract interesting in order to make the reader want to continue to read the abstract
(Belcher, 2009). Therefore, a good abstract must be created by the writers as worth as the whole content of research article in order to be able to represent what messages want to be expressed in the abstract. Abstract allows readers who may be interested in the paper to quickly decide whether it is relevant to their purposes and whether they need to read the whole paper.One the characteristics of good abstract is its coherence. Writing an abstract with its coherence is not only difficult for 
university student but also hard for lecturers. Creating a coherent and cohesive academic writing is also complicated for students at the tertiary level. In fact, most tertiary students would agree that academic writing particularly writing a research thesis is the hardest task to complete (Evans \& Gruba, 2002; Emilia, 2008). Meanwhile, Jones (2009), in his comparative study in academic writing between native and non native students in Australian tertiary context, points out that writing coherently and cohesively in academic context is still regarded as a complex matter for both native and non native students.

Moreover, similar findings from several well-established researches recommends that analyzing students' writing with the emphasis on meaning and function, Theme-Rheme, and textual metafunction of text have provided an effective framework for identifying coherence in students' texts (Vande Kopple, 1991; Bloor \& Bloor, 1992; Eggins, 2004; Schleppegrell, 2004, 2009; Christie \& Dreyfus, 2007; Wang, 2007). As a result, it has been suggested that analysis on textual coherence using Theme Rheme progression can be useful for academic writing

Many researchers had analyzed about abstract in many aspect. Safnil (2014) had conducted the Rhetorical of abstract. According to Safnil (2014) reviewed clearly about many researchers' ideas about the move of abstract. In his Research Article stated that there are four possible moves of abstracts (problem, aims, method, and results), only three are considered compulsory (aims, method and results) while problem is optional. In his research article, he focused to analyze socialhumanity field. On the contrarty, the researcher takes another field, non-native speaker of English, to analyze in this research. Similar idea, Bathia suggests that an abstract consist four aspect of research; they are 1) the purpose, 2) the method, 3) the results, and 4) the conclusion. In addition, it should present the purpose of the work to the reader and also to encourage the reading of the complete work. Scientific texts (papers, reports, theses, etc.) have a well-defined structure that can be categorized as: Introduction, Development, and Conclusion (Safnil, 2014; Swales, 1990)

Another had conducted the coherence analysis in another section of research article. With regard to students' ability to create a coherent and cohesive writing, several studies have been conducted to investigate the coherence and cohesiveness in students' academic writing. Among those are a study conducted by Emilia et al (2008 and 2010) that reports students' difficulties in writing discussion chapter of a research thesis coherently and critically. To overcome the problem, Emilia proposes a teaching program with a view to nurture students' ability in writing a discussion chapter so that they have the capability in writing a thesis critically and coherently.

Another study which focuses on coherence and cohesiveness in students' academic writing is also conducted by Watson, Khongput, and Darawasang 
(2007). They found that student's essays lack coherence and cohesion and suggested to write comments, feedback, or side notes on students' academic essay particularly to guide the students in recognizing the lack of coherence and cohesion in their essays.

The relevant study by Souza and Feltrim (2011) which is conducted an analysis of textual coherence in academic abstracts written in Portuguese. The main purpose of his work is to propose four dimensions of analysis concerning textual coherence in academic abstracts. These dimensions take into consideration the rhetorical structure of abstracts, as proposed by Feltrim et al (2003). abstracts from Bachelor theses written in Brazilian Portuguese were analysed according to the proposed dimensions and the results for each of them were presented.

By taking into account the manual analysis performed on the corpus, he observed that from the four proposed dimensions, at least three can be automated by means of computational resources: Dimension Title, Dimension Purpose and Dimension Gap-Background. In these three dimensions we have observed the existence of patterns concerning the rhetorical structure and aspects of coherence, he differently from the fourth dimension, Dimension Linearity-break. He observed in Dimension Title that the sentences with a higher semantic relationship with the title of an abstract were the sentences of Purpose category. Moreover, he observed problems of coherence in abstracts in which the relationship of the title and the sentences of the Purpose are low. Both categories of sentences, title and Purpose, summarize the main purpose of the work, each in its proportion and, therefore, a high relationship between these sentences is expected to led to a greater level of coherence.

The importance of academic writing, TEFLIN is important for the researchers because it is a medium for research article publication in academic writing. It is also a medium for them to convey their ideas and to share with another researchers. One of them is "Teaching English as a Foreign Language in Indonesia (TEFLIN). TEFLIN publish the research in international area, so it must be have some characteristic to pass the selection of TEFLIN itself, one of them is the coherence of the text.

Thus, based on the previous study had been done, there are many researchers had conducted the research about the analysis of abstract in other aspect and conducted the coherence analysis in other aspect of research article. So, it is the main reason for the researcher to analyze coherence in abstracts especially in TEFLIN article in applied linguistisc written by Indonesian speaker espeially in TEFLIN.

Coherence is continuity in meaning and context and concerns with underlying phenomenon in the text. Coherence refers to the way a group of clauses or sentences relate to its context or in other words coherence in a text refers to their contextual property which means the way in which it relates to and makes sense in the situation in which it occurs (Halliday and Hasan 1976 in Eggins, 2004: 29; Paltridge, 2006: 139). 
In addition, according to Systemic Functional Linguistics, coherence embodies two aspects of context: the outer context of text is acknowledged as context of culture which is known as generic coherence and the inner context of text is known as situational or registerial coherence (Butt et al, 2000; Eggins, 2004).

Context of culture or generic coherence refers to a possible meaning that represents and is influenced by its broader sociocultural environment, such as ethnic group, institution, ideology, or social convention or in other words a generic coherence occurs in a particular communicative context, event, or genre. This means that generic coherence is used to identify its social purpose from the clauses or the coherence properties included in the text (Butt et al, 2000; Eggins, 2004).

The latter term, situational or registerial coherence refers to the language use in a more specific situation or the situation where the text occurs, accordingly; the situation shapes the function and the meaning of the text (Butt et al, 2000; Eggins, 2004). In terms of the situational or registerial context of coherence, Eggins (2004: 29) describes three different systems of grammar: field, mode, and tenor system.

Field system is used to point out the language used to talk about what is happening, what will happen, and what has happened. Mode system reflects the role of language that is employed in the interaction, and tenor system associates with the role of relationship between the interactants (Butt et al, 2000; Eggins, 2004).
As explained above, the three parameters of context of situation (field, tenor, and mode) affect linguistic choices of the speaker or writer in the sense that these parameters reflect major functions of language and these functions manifest in different grammatical features of text (Butt et al 2000, Eggins, 2004).

The three parameters above are instilled in the three distinct modes of meaning:1) ideational, 2) interpersonal, and 3) textual. These three functions are then known as the linguistic system of metafunctions which represent different purposes in the development of the text (Butt et al, 2000; Eggins, 2004; Halliday and Matthiessen, 2004; Emilia, 2010).

Theme and Rheme system is a basic form, a source for organizing and constructing the clause message, and also for assigning textual prominence to elements within the clauses in textual organization (Halliday, 1983: 53; Matthiessen, 1992: 47). Thus, by organizing and examining the patterns Theme and Rheme, the meaning of the whole text and how clauses are organized or combined can be understood. With regard to Theme and Rheme as the clause message system, Halliday and Matthiessen (2004) define the practical implementation of Theme and Rheme in the sentences. Sentence may be divided in terms of given information (Theme) and new information (Rheme) which means Theme typically holds several old or given information and provides particular setting as a mean to keep the contextual unity in the sentences. Furthermore, Halliday (1994: 39) elaborates 
that Theme is what the speaker has in mind to start with and also organizes the clause as message, but the position is not what defines the Theme: it is a mean which realizes the function of the Theme.

In addition, McCarthy (1990: 55) explains that Theme is clauses that signal the topic in the sentence, yet, do not tell about the rest of clause or topic, and what comes after Theme or the rest of the clause is known as Rheme or comment that develops the topic or Theme. Gerot and Wignell (1997: 103) also define Theme as an element which comes first in the clause and commonly immediately precedes the main verb of the clause and Rheme as the element which includes the main verb and all other remaining constituents of the sentences.

There are three different types of Theme: topical (experiential), interpersonal, and textual element (Emilia, 2010: 17). Topical element of the clause is to which a transitivity function can be assigned or the first element of transitivity in the clause (Gerot and Wignell, 1994: 132; Eggins, 2004: 32). According to Martin, Matthiessen, and Painter (1997: 22), topical (ideational) Theme can be recognized as the first element in the clause which expresses kinds of representational meaning that attaches a transitivity role such as actor, behaver, senser, carrier, or circumstance. In other words, topical or ideational Theme is technically a function from the transitivity structure of the clause and it might be a participant, process, or circumstance in the first element of the clause. Thus, to consider whether the first Theme is topical, it should fulfill the slot that functions as participant, process, or circumstance (Butt et al, 2000: 136).

According to Halliday and Mathiessen (2004: 74), unmarked topical Theme is a nominal group or nominalization that serves as the subject. It is an element that occupies the Theme position of the clause that conflates with grammatical subject (Halliday, 1985: 44). In addition, Martin, Matthiessen and Painter, (1997: 22) also define that unmarked topical Theme can be recognized if the first topical element of a declarative clause is also the subject of the clause.

Besides, unmarked topical Theme is used to emphasize the topic of the clause and to highlight the field under discussion (Emilia, 2005: 166). In marked Theme, an element, other than the subject occupies the Theme position, so a condition is created for the presence of marked Theme. Martin, Matthiessen, and Painter (1997: 22) state that non-subject Themes are marked Themes.

Interpersonal Theme is when a constituent is labeled as a mood in the beginning of a clause (Martin, Matthiessen, and Painter, 1997; Eggins, 2004; Emilia, 2010). Interpersonal Theme deals with modal/comment, adjunct, finite verbal operator in yes/no interrogative, mood, polarity or any combination of vocatives or personal names (Martin, Matthiessen, and Painter:, 1997). The constituents that can function as interpersonal Themes are: The finite, Modal adjunct as in Mood Adjunct and Comment adjunct, Mood Adjunct, Vocative Adjunct, and Wh Elements or Polarity Adjunct. 
Textual Theme is the constituents which do important cohesive work in relating clause to its context (Eggins, 2004: 305). The Textual Theme covers continuatives (small set of discourse items which signal that a new move is beginning such as: yes, no, oh), structural elements (coordinates and subordinates), conjunction, and conjunctive adjunct which relate the clause to the preceding text (e.g., in other words).

In addition, the use of Textual Theme such as conjunction and the like indicates that the text is highly written (Emilia, 2010). In particular, Textual Theme is important in structuring the texts because the Theme operates at sentence or clause complex level (Gerot and Wignell, 1994: 119). According to Martin, Matthiessen, and Painter (1997: 25), Textual Themes are: Structural Conjunction (Linking two clauses in a coordinating relation or marking one clause as dependent on another), Conjunctives (Providing a cohesive link back to previous discourse), Continuative (continuity adjunct as Theme and the commonest continuity items).

Thematic progression (TP) as a theory was first propounded by Frantisek Danes in 1974, who argue that 'the paragraph is a content unit delimited by its boundaries and its inner coherence'. Thematic progression is Theme Rheme development employed in the text to organize the ideas through the Theme which is employed in the clauses (Butt et al, 2001: 134). Thus, how thematic elements succeed each other can be observed through its development pattern (Eggins, 1994: 324). Furthermore, thematic progression is a important aspect to trace the global flow of information throughout the text. In addition,Eggins (2004:326) divided them into three patterns are Theme reiteration, Zigzag pattern, and Multiple Rheme pattern.

In the reiteration pattern, the same element appears repeatedly and is used frequently as a starting point of message in the sentences, but is rarely used to develop the Rheme. However, the Theme reiteration is used to create a strong topical focus (Eggins, 2004). The Zigzag pattern ties a text with a sense of continuous development because new information in the preceding clause becomes the starting point of the following clause (Vande Kopple, 1991; Eggins, 2004; Emilia, 2005; Christie and Dreyfus, 2007). The third pattern is multiple - Rheme pattern. This pattern occurs when the Theme of one clause introduces a number of different pieces of information then the different pieces of information are written as the Theme in following clause in sequence paragraph in the text (Eggins, 2004: 325). The multiple Rheme pattern can be used to organize a paragraph, but this pattern can also occur across paragraphs.

Additionally, Danes in 1974 divided Thematic Progression into four main patterns: first, Zig Zag theme contains two or more sentences in which each rheme becomes the theme in next sentence. Second, constant theme which he also referred to as theme reitaration. In this, (theme reitaration or constant theme) pattern is picked up and repeated at the beginning of next clause, signaling that each clause will have 
something to say about the theme. Thus, it consists of two or more sentences with the same theme. Third is Multiple (Split) pattern. It has a certain rheme which is divided or split into two or more parts, each of which is developed separately as the theme of the following sentences. The last is TP with derived T's which is "hypertheme" develops individually different theme of each .

\section{METHOD}

The preceeding study illustrated the step involved in content analysis. First, specifying the phenomenon to be investigated; this research had investigated the coherence of the abstracts. Second, selecting the media from which the observations were to be made; this research selected 100 abstracts from the TEFLIN articles. Third, formulating exhaustive and mutually exclusive coding categories; this research formulated the theme-rheme and thematic progression of the abstracts.

Next. Deciding on the sampling plan to be used;this research used 100 abstract of TEFLIN 2015. Then, training the codes. The last, analyzing the data. For the first step, the researcher analyzed the TEFLIN abstracts by using theme rheme system which had three categorizes. They were: topical (experiential), interpersonal, and textual element. This is an example which was taken from one of the TEFLIN abstracts. Example of Topical theme analysis in TEFLIN abstracts. (see appendix1)

\begin{tabular}{|l|l|}
\hline Children & $\begin{array}{l}\text { are easier to interpret the meaning of a sentence without having } \\
\text { tounderstand the meaning of each word }\end{array}$ \\
\hline Children & $\begin{array}{l}\text { are very creative in using the } \\
\text { language }\end{array}$ \\
\hline Theme & Rheme \\
\hline
\end{tabular}

For the second step, the researcher analysis the progression thematic by using four patterns, they are: simple linear pattern, constants pattern, multiple pattern and

Children are easier to interpret the meaning of a sentence without having to understand the meaning of each word,
(T1)
(R1)

children are very creative in using the language

(T1)

(R2)

they like to repeat the words they do not understand

Based on the analysis above, this abstract commonly used reiteration abstract pattern with derived theme. This is the example how to analyze the TEFLIN abstract. 
For the last step, to know how coherence's quality in TEFLIN abstract, the researcher used The Parameter of Coherence Proposed by Eggins (2004).

Table 2.7: The Parameter of Coherence Proposed by Eggins (2004)

\begin{tabular}{|l|l|l|}
\hline No & $\begin{array}{l}\text { Level of } \\
\text { Coherence }\end{array}$ & \\
\hline 1 & Good & $\begin{array}{l}\text { If the type of thematic progression is constant in one type each } \\
\text { paragraph. }\end{array}$ \\
\hline 2 & Fair & $\begin{array}{l}\text { If the type of thematic progression is inconstant or change from } \\
\text { one type to others type each paragraph. }\end{array}$ \\
\hline 3 & Less & If new theme(s) is/are created in the middle of paragraph. \\
\hline 4 & Poor & If there is no thematic progression used. \\
\hline
\end{tabular}

\section{FINDING AND DISCUSSION}

The result in this section presented the data of theme choices dominantly applied in TEFLIN abstracts in applied linguistics written by Indonesian speaker. The types of theme applied in abstracts were analyzed based on Halliday's type of Theme. The types of theme in this TEFLIN abstracts can be categorized as textual Theme, topical Theme, and interpersonal Theme. The table 4.1 described types of Theme dominantly applied in 100 TEFLIN English abstracts in applied linguistics.

Table 4.1: Types of Theme in TEFLIN Abstract

\begin{tabular}{|c|c|c|}
\hline Types of Theme & Frequency & Percentage \\
\hline Textual Theme & 92 & $45 \%$ \\
\hline Interpersonal Theme & 12 & $6 \%$ \\
\hline Topical Theme & 100 & $49 \%$ \\
\hline Total & 204 & $100 \%$ \\
\hline
\end{tabular}

From table 4.1, it was shown that Topical Theme was the theme dominantly applied in TEFLIN abstracts in applied linguistics written by Indonesian speaker. Topical theme was applied in 100 abstracts. Abstracts. It was about $49 \%$ from the usage of theme in TEFLIN abstract. It meant that all of the researchers used this theme in their abstracts.

Moreover, the data also indicated that textual theme is the second prominent Theme appears in TEFLIN abstracts. Textual theme appeared in 92 from 100 abstracts or it was about $45 \%$ from the usege of theme, about 92 researchers used textual theme in their abstracts, and only 8 
researchers did not use this Theme to connect the previous sentence to the next sentence.

The last and less used theme in the International abstracts was interpersonal Theme. It just appeared in 12 abstracts from 100 abstracts. Only 12 reserachers used this theme while 84 researchers did not use this theme in their abstracts. It means that only a few of researcher use the interpersonal Theme as a mood in the beginning of the clause.

The example from extract 1 was taken from abstract number 22. It show that the Structural Conjunction but appeared in the first line. Here, the researcher just use one textual theme, it was structural conjunction but. It was said in the sentence "TEFLIN conferences have been held 61 times, but the TOFEL scores of Indonesia learners of English are low", the structural conjunction but is used to show the contradictive from the previous sentence to the next sentence. The other example of Textual Theme in abstracts section.

The extract 6 was taken from abstract Number 6. It shows that marked topical Theme dominantly used in this abstract. The researcher used marked topical theme to show the topic of the sentences. The researcher used 5 marked. It can be seen in line 1, 2, 7 and in line 12. In line 1, marked theme since its advent to the present time was used to show the new topic. It was same with the other marked in this abstract. Moreover, besides using the marked topical theme, the researcher also used the unmarked topical theme which was shown as the subject of the sentences in line 4 using "it" and in line 6 using "the student".

It also shows that besides marked topical theme and unmarked topical theme, textual theme such as since in line 1 , but in line 4 , and which in line 7 were used in this abstract section. Structural conjunction was also the most common textual Theme to appear in the clause of Internatioal conference abstract. Textual Theme almost appeared in the first part of the Theme or come before interpersonal Theme. The purpose of using textual Themes by the researcher was to give the linking functions from the previous element to the following elements.

The analysis in this sub-section has provided the information on types Theme used in TEFLIN of English abstracts in applied linguistics written by Indonesian speaker. As a conclusion, the selection of Theme can be varied from one abstracts text to another text. Yet, researchers should be careful with the selection of Theme used in their abstracts section since the use of particular theme can affect the way information is being developed, maintained, and generally affect the coherence of the text.

Overall, the analysis of Theme choices in this section can be used to answer the first question of this study. The next discussion is related to thematic progression found in TEFLIN of English abstracts in applied linguistics.

The analysis on Thematic Progression used by the researchers in TEFLIN of English abstracts in applied linguistics written by Indonesian speaker. Based on Theme choices employed by the researchers 
in TEFLIN of English abstracts in applied linguistics written by Indonesian speaker, the data showed that there are three thematic patterns found in the abstracts section, namely Continuous (Reiteration) pattern, (Simple Linear) Zig Zag pattern, and Multiple or Split Theme. The analysis in this section concerns with the flow of information from Theme to Rheme.
The analysis also deals with the development of Theme and Rheme which is used to convey their ideas in the abstracts section. The table below shows types of thematic progression pattern is applied in TEFLIN of English abstracts in applied linguistics written by Indonesian writer.

Table 2: Thematic Progression of Abstracts

\begin{tabular}{|l|c|c|}
\hline \multicolumn{1}{|c|}{ Types of Thematic Progression } & Frequency & Percentage \\
\hline Continous (Reiteration) Pattern & 62 & $38 \%$ \\
\hline Zig Zag ( Simple Linear) Pattern & 89 & $55 \%$ \\
\hline Multiple (Split) Pattern & 12 & $7 \%$ \\
\hline Tp with Derived (T's) Pattern & 0 & $0 \%$ \\
\hline \multicolumn{1}{|c|}{ Total } & $\mathbf{1 6 3}$ & $\mathbf{1 0 0 \%}$ \\
\hline
\end{tabular}

Table 2 presented the data of Thematic Progression was used in TEFLIN of English abstracts in applied linguistics written by Indonesian writer. In the first position, Zigzag (Simple Linear) Pattern as the basic pattern of Thematic Progression was applied 89 times or it is about $55 \%$ from $100 \%$. In the second position of single pattern is Continuous (Reiteration) Pattern.
It is applied 62 times from 100 abstracts or it is baout $38 \%$. The last and the less of Thematic Progression was applied is Multiple (Split) Pattern. It was only appeared 12 times from overall abstracts. None of them use Derived TP.

The example below is the example of Theme Reiteration in the abstract section: 


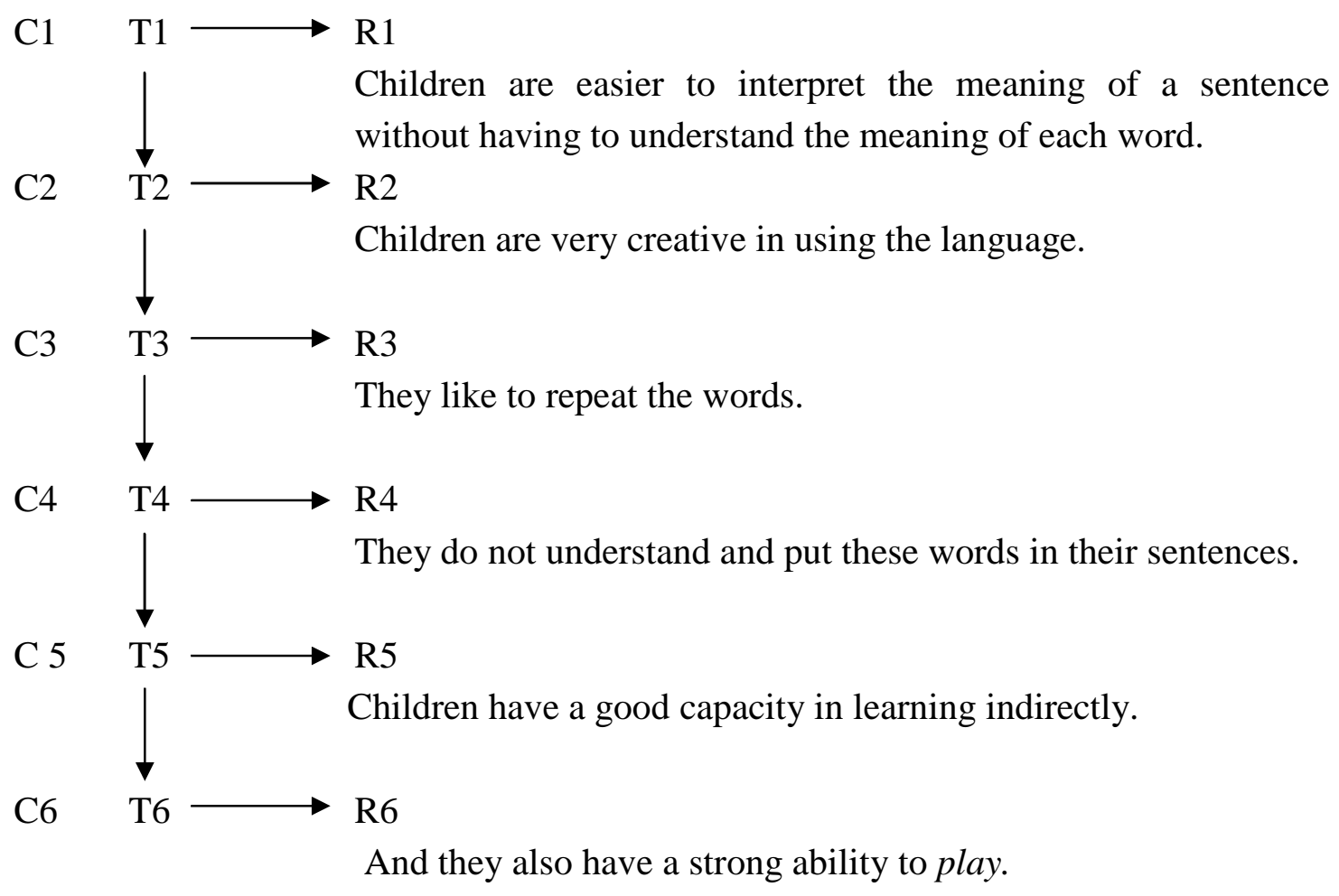

From the table above, the researcher use the same Theme in his abstract. The word "Children" appears three times. It is from T1 to T6. He used the same Theme continuously in his abstract. Moreover the researchers use "they" as the pronoun or personal reference of children as the subject. Whether the Rheme of the abstract have different one to another, the Theme always repeat again and again. It means the researcher attempted to provide "a focus in his/her writing in order to be clear with the topic being discussed.

Zigzag pattern can be found in TEFLIN of English abstracts in applied linguistics written by Indonesian speaker. Here is the example of zigzag pattern from the TEFLIN of English abstracts in applied linguistics written by Indonesian speaker. 
The Example of Zigzag Pattern

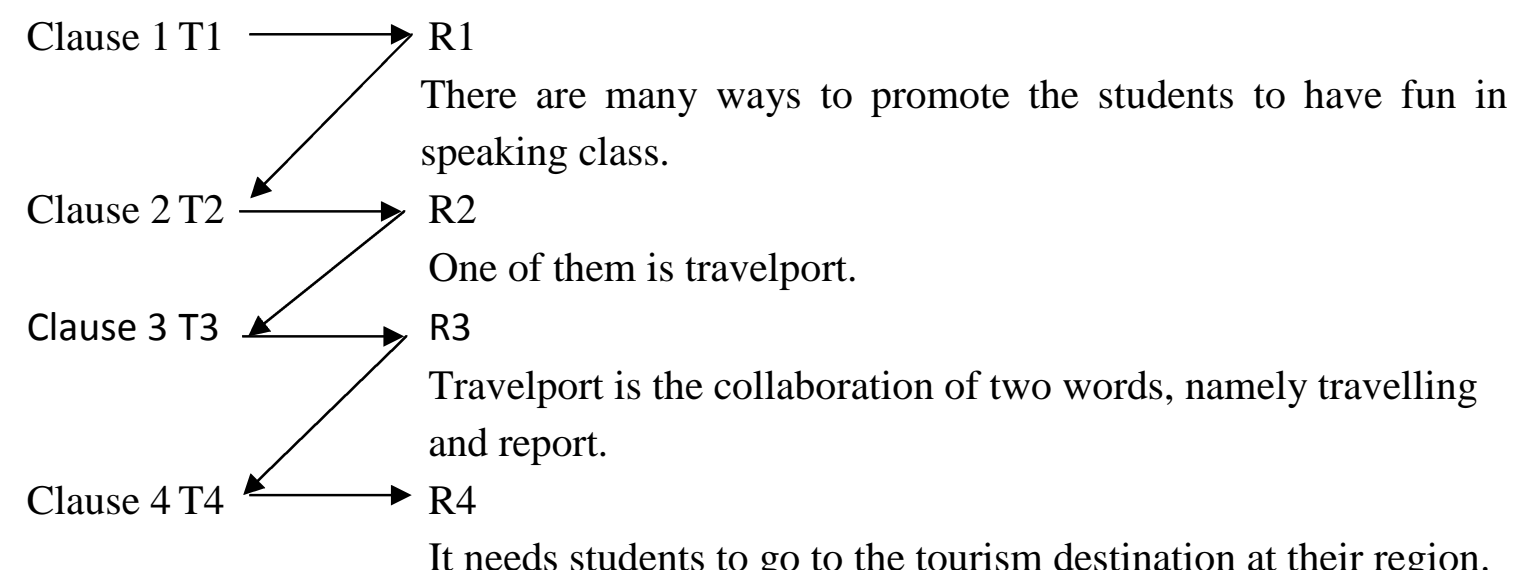

In the example above, indicate that the researcher use Zigzag (Simple Linier) Pattern. It can be seen in the example above that T9 is same with T11. "Lack of knowledge which part of the articles should be underlined "as R11 becomes Theme in clause 12. While R12 that is "provide some suggestion" is become $\mathrm{T}$ in clause 13. It is happened again in the next sentence. The words "should receive more attention" as $\mathrm{R} 13$ become $\mathrm{T}$ in clause 14. It is important to use Zigzag pattern in research or academic writing because this is a way make their writing have a consistent flow of information and to provide logical connection between their writing. There are new information in the beginning of every clause. Clause 2 shows that the element which is introduced in the Rheme of first clause is established as a Theme in the following clause 2 . It is appeared again in the next clause.

Multiple or Split pattern can be found in TEFLIN of English abstracts in applied linguistics written by Indonesian speaker. Here is the example of Multiple or Split pattern from the TEFLIN of English abstracts in applied linguistics written by Indonesian speaker. 
The Example of Multiple or Split Pattern



From the example above, it can be described that R5 "are used as indicator in assessing the development are vocabulary, pronunciation, structure, fluency, and comprehension" introduces a number of different pieces of information, the R5 are written as the Theme in clause 6 until clause 9. "The improvement of vocabulary "be the Theme in clause 6, "The improvement of pronunciation"becomes the Theme in clause 7, "The improvement of structure"be the Theme in clause 8, and "The improvement of vocabulary"becomes the Theme in clause 9.

Coherences' quality of the research article abstract section in TEFLIN abstracts in applied linguistic is based on thematic progression. The result showed that there are two coherences' quality is indicated in this research. They are fair and less quality. The table below shows the result of coherences' quality of the research article abstract section in TEFLIN abstracts in applied linguistic based on the matic progression. 
Table 3: The Level of Coherence in Abstracts Section

\begin{tabular}{|c|c|c|}
\hline Coherence Quality & Frequency & Percentage \\
\hline Good & 0 & 0 \\
\hline Fair & 94 & $94 \%$ \\
\hline Less & 6 & $6 \%$ \\
\hline Poor & 0 & 0 \\
\hline Total & 100 & $100 \%$ \\
\hline
\end{tabular}

In table 3 , it is shown that from 100 number of abstract, none of them can be categorized as good and poor coherences. About 94 abstracts or $94 \%$ of theme can be categorized as fair coherences' quality and only 6 abstracts are included as poor coherences' quality. It can be concluded that the coherence quality of 2015 TEFLIN article abstract can be categorized as fair coherence quality. Here are some examples of abstract in the level of fair quality.

The example of fair quality of abstract section



Clause $3 \mathrm{T3}_{\mathrm{T}} \mathrm{P}_{\mathrm{R} 3} \mathrm{R}$

Clause $4 \quad T 4 \longrightarrow R 4$

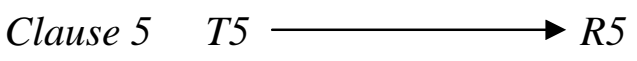

The washback effect of a high stakes test may vary in different situations.

It can be either positive or negative, and strong or weak.

One of the factors influencing the washback of a high stakes test is the suitability of the curriculum implemented with the test content.

This study is aimed at investigating the English teachers' perception on the washback effect of the English National Examination as a high stakes test.

Moreover, the way teachers keep abreast with the demands of curriculum and the test and will be revealed.

From the example above, the researcher use two thematic progressions; Reiteration
Pattern and Zigzag Pattern. This abstract is included in fair quality of abstract because 
the researcher use inconstant thematic Reiteration patter to Zigzag Pattern. progression, he change his pattern from

In addition, here are some examples of less quality of abstract.

Clause $1 \quad T 1 \quad R 2$

Since its advent to the present time Internet has contributed to English language teaching and learning.

Clause $2 \quad T 2$

$R 2$

$\begin{aligned} & \text { In English for Specific Purpose }(E S P), \text { for } \\ & \text { example, Internet does not only provide materials } \\ & \text { that are ready for use for teaching and learning. }\end{aligned}$
Clause $3 \mathrm{T3} \longrightarrow$

But, it also offers such a facility as e-learning into which the teachers of English can insert or upload their teaching materials and from which the students can learn those materials.

Clause $4 \quad T 4$

$R 4$

To be concerned with ESP teaching, this paper addresses its discussion on teaching Legal English (LE) for law students via e-learning provided by Information Technology Centre at the University of Jember in the program of Integrated Information System (SISTER).

The example above, is taken from the abstract 4 , it can be categorized as less quality of abstract because the researcher use thematic progression in the middle of the sentences. He used Zigzag pattern in the second clause. It can be seen that R2 becomes $\mathrm{T} 3$ in the third clause.

\section{DISCUSSION}

The finding of the reserach were; first, the types of theme are dominantly applied in 2015 TEFLIN of English abstracts in applied linguistics written by Indonesian speaker; second, the types of thematic progression are dominantly applied in 2015 TEFLIN of English abstracts in applied linguistics written by Indonesian speaker; and the last, the quality of abstracts applied in 2015 TEFLIN of English abstracts in applied linguistics written by Indonesian speaker.

The types of Theme in this TEFLIN abstracts can be categorized as textual theme, topical theme, and interpersonal theme between three type of themes, Topical Theme is types of theme dominantly applied in 2015 TEFLIN article abstracts in applied linguistics written by Indonesian speaker. It may be topical theme can describe the clear focus in the sentences. Thus, the reader know the main focus of the sentences, it perhaps the 
participant of the sentences as the subject in the sentence. It helps the reader know the subject of each sentence. Emilia (2005: 187) also said that Theme provide clear focus in the clause. Moreover topical Theme is to show that nominal group or nominalization that serves as the subject and fills the slot of participant, process, or circumstance (Halliday and Mathiessen, 2004: 74).

Further, the second theme dominantly used in the abstracts section is textual theme. In this research, many of researchers use conjunction "that" to link one sentence to the other sentence but appear in one clause. The first sentence was as the dependent clause and the other as the independent clause. The researchers, who used textual theme, can be said that they have good coherence because they can connect one sentence to the other appropriately.

Martin (1997) stated when the textual theme is mostly appeared in the initial clause, it means that they give the linking functions from the previous element to the following elements. Providing textual Theme in the initial position suggested that researcher had emerging awareness to provide connection between previous and following clause so that the information between clauses appeared tobe more coherent. It is stated by Butt et al, (2000) that Textual Theme is well signposted connections between messages since it is also possible to tell the purpose of a text by examining its textual theme.

One types of textual theme never appear in abstract section, it is continuatives. One of the examples of this theme is "yeah". In academic writing the continuatives "yeah" cannot appropriate word to link the sentences.

The last and the less used of theme is of interpersonal theme, the less used of interpersonal theme perhaps this theme just give emphasis of thing. This is in line with the nature of academic text which avoids involving too much interaction between speakers or writer and the positions they are taking (Butt et al, 2000: 138).

The analysis has provided the information on types theme used in 2015 TEFLIN of article abstracts in applied linguistics written by Indonesian speaker. As a conclusion, the selection of theme can be varied from one abstracts text to another text. Yet, researchers should be careful with the selection of theme used in their abstracts section since the use of particular theme can affect the way information is being developed, maintained, and generally affect the coherence of the text. Overall, the analysis of Theme choices in this section can be used to answer the first question of this study

This second section provides the analysis on Thematic Progression used by the researchers in TEFLIN article abstracts in applied linguistics written by Indonesian speaker. There are four thematic patterns found in TEFLIN abstracts, namely continuous (reiteration), zigzag pattern, and multiple or split theme. Zigzag (simple linear) pattern is the dominantly. The high usage of this theme found in the abstract may be equal to what Danes (1974), argues about simple linear pattern is the basic 
pattern of thematic progression.

The use of zigzag simple linear pattern in this abstract can be shown that the researchers can built a new Theme based on the rheme in the previous clause. It probably means that by using zigzag pattern the researchers acknowledged the function of this pattern and have an effort to develop new information in there. The Rheme in Zig Zag pattern is developed and became the theme in the next clause. Butt (2000) also stated that this Theme can provide focus and moving the topic forward.

Furthermore, the use of zigzag pattern is a way to maintain and develop the information in writing. So, may be it is important for researchers to use zigzag pattern in their research or academic writing because this is a way that make their writing have a consistent flow of information and to provide logical connection between their writing.

By applying Zig Zag pattern, the researcher showed capability to build newly introduced information in its Theme which is derived from the previous Rheme (Eggins, 1994: 325).

The second thematic progression is reiteration pattern. This theme used thematic development that repeatedly make uses the same theme in the Clause.

The repetition word may be indicates that the researcher attempted to provide "a focus in his/her writing in order to be clear with the topic being discussed. However, this strategy prevents the topic development in the text. The researchers repeatedly use the same unmarked topical element. If the same topical element is used frequently, it means that the researchers cannot develop the idea.

Eggins (1994) said that, the text will not be developed and this makes the information in the text under developed if the repetition words always appear.

Some of researchers use pronoun or personal reference of their abstract because they do not want to make their abstract like the monotonous repetition. Using different elements or the combination with other elements indicates that the student avoids "the monotonous repetition" (Eggins, 2004).

Over usage of this theme may lead the lack of deep explanation of the ideas introduce as the writer does not expand the information contained in the rheme. Multiple or Split pattern can be found in TEFLIN of English abstracts in applied linguistics written by Indonesian speaker but just a few researchers used this theme.

Derived theme never applied in abstract section. It is possibly happened because this Theme is difficult to judge. The reason for this is still debate on whether derived theme is one type of thematic progression or not. (McCabe, 1999)

The third question is how is the coherences' quality of the conference abstract section in TEFLIN abstracts in applied linguistics written by Indonesian speaker

The result shows that there are two coherences' quality is indicated in this research. They are fair and less quality. It may be happened because the use of thematic progression, the writer can analyze the quality of abstract. Fair quality of abstracts is the most quality in abstract 
section. It perhaps, the researchers used more than one thematic progression in one abstract. They did not use constant thematic progression in each sentence of their abstract.

While, less quality happened because of using thematic progression in the middle of the sentences. Eggins (2004) states that if the type of thematic progression is inconstant or change from one type to others types, the text is categorized as fair.

Having known the result of this study as stated previously in this research and as related to the some theories and previous study, this study have some similarity with the other studies. The types of themes are usually used is topical theme. The commonest thematic progression is simple linear (zigzag) pattern (Marfuaty, 2015).

Although having similarity, this study have some differences in coherences' quality. In this study, almost of the sample have fair quality of abstract, while in the other studies the students in universities have lack of coherence (Feltrim, 2003 ; Darawasang, 2007). Moreover, Marfuaty (2015) in her research which had conducted coherence analysis in Jakarta post, the result of her study was all of the sample have fair quality of abstract.

In addition, this research of course has the positive side and negative side or the weaknesses and the strengths. The strength or positive side of this study is this study has focused for analyzing the abstracts in TEFLIN. Thus, the readers know the coherences' quality of abstracts in TEFLIN.

In contrary, there are some limitations in doing this research. First, the researcher want to use more than one inter-rater, because of the limitation of the time, the researcher only used one inter-rater to validate the data. Second, calculation of percent agreement,the researcher only make $10 \%$ from the sample to represent the whole percentage of agreement.

Relating to the research discussion, this research contributes theoretical and empirical finding, the themes which are dominantly used in 2015 TEFLIN article abstracts is topical theme. The thematic progressions which are dominantly used in is simple linear pattern. Coherences' quality of the research article abstract is fair quality.

Having known the coherences' quality of astracts in TEFLIN abstracts almost fair, the other researchers or students can follow to write abstracts or others coherently. From gained literature and gained data in this study and previous study, the question appearing whether it is important for the other researchers to analyses the abstracts in other aspect to make the readers or others researchers make their abstracts is more interesting.

The other question appears whether it is important for the further researchers to analyses the coherence, thematic progression, and the coherenres' quality in others aspects of english writing or in other parts of academic writing to make contribute the coherences' quality of an academic writing. Thus, through this study it is hoped that there will be further study to conduct this in order this study could give more significance contribution in writing English coherently. 


\section{CONCLUSION}

This study attempt to find out: 1) the themes which are dominantly used in 2015 TEFLIN article abstracts written by nonnative speaker of English. 2) the thematic progressions which are dominantly used in 2015 TEFLIN article abstracts written by non-native speaker of English. 3) coherences' quality of the research article abstract section in 2015 TEFLIN article abstracts in applied linguistic based on thematic progression.

The conclusions from the coherence analysis of 2015 TEFLIN article abstracts in applied linguistic werre taken from the data analysis in Chapter Four. The results indicated that researchers have used various types of themes and thematic progression patterns. The theme mostly used in the TEFLIN abstracts was topical theme. Then was followed by textual theme and the last was interpersonal Theme but these two Themes were less found in TEFLIN abstracts.

In addition, the results of coherence analysis of 2015 TEFLIN article abstracts in applied linguistics written by Indonesian speaker clearly signified that $\mathrm{Zig} \mathrm{Zag}$ (Simple Linear) pattern was the most prominent thematic progression used. Next, continous (reiteration) pattern was the second thematic progression, multiple (split) pattern was the last thematic progression and none had derived thematic progression pattern.

Then, the quality of abstract in 2015 TEFLIN article abstracts in applied linguistics written by Indonesian speaker almost have fair quality, just a few of them have less quality and none of them has good or poor quality of abstract.

Finally, it can be concluded that 2015 TEFLIN of English abstracts in applied linguistics written by Indonesian speaker can be categorized as good abstract based on its coherence.

\section{REFERENCES}

Alam, Bryman. (2003). Triangulation: Encyclopedia of social science research method. Chicago: Sage publication.

Arikuntoro, S. (2006), Prosedur penelitian suatu pendekatan praktik. Jakarta: PT rineka Ciptae.

Arsyad, Safnil. (2014). The discourse structure and linguistic feature of research article abstracts in english by indonesian academics. ASIAN ESP Journal, Vol.10, issue2, pp: 191-224.

Ary, Jacobs \& Seronsen. (2010). Introduction to research in education. Canada: Matrix production.

Belcher, Wendy Laura.(2009). Writing your journal article in twelve weeks: a guide academic publishing success. Califomia: SAGE Publication, Inc.

Bathia, K. V. (2006) The rhetoric of article abstract: a sweep through the literature and a preliminary study. Journal of Bahasa dan Seni, 43 (2) 174 189. Retrieved October 1, 2015. From http://sastra.um.ac.id/wp-content/October, 2009.

Bloor, M. and Bloor, Thomas. (1995). The practice of critical discourse analysis. London: Longman.

Bloor, M., \& Bloor, T. (1992). Given and new information in the thematic organization of text: An application to the teaching of academic writing. Occasional Papers in Systemic Linguistics, 6(1),33-43.

Brown, D. (2001). Teaching by principles: An interactive approach to language pedagogy. New York (2nd:Longman). 
Butt, D., Fahey, R., Feez, S., Spinks, S., \& Yallop, C. (2000). Using functional grammar: an explorer's guide. Sydney: Southwood Press.

Butt, D. G., Lukin, A. et al. (2004). Grammar-The first covert operation of war.'discourse society. 15: 267-290.

Carter-Thomas, S. (1999). Thematic networks and types. Asp, ia Reveu du Geras, 23-26, 139-147.

Christie, F., \& Dreyfus, S. (2007). Letting the secret out: Successful writing in secondary English. Australian Journal of Language and Literacy, 30(3), 235-247.

Coffin, C.(2001). Theoretical approaches to written language-A TESOLPerspective.

Danes, Frantisek. (1974). Functional sentence perspective and the organization of the text. In Danes, Frantisek (ed.), Papers on Functional Sentence Perspective. Prague: Academia, 106128.

Denzin, N. K. (1970). The research act in sociology. Chicago: Aldine.

Eggins, S. (2004). An introduction to systemic functional linguistics. London: Continuum Intemational Publishing Group.

Emilia, E. (2005). A Critical Genre-Based Approach to Teaching Academic Writing in a Tertiary EFL Context in Indonesia. Unpublished Dissertation in Department of Language, Literacy and Arts Education Faculty of Education. Melboume: The University of Melbourne.

Emilia, E. (2008). Menulis tesis dan disertasi. Bandung: Alfabeta.

Emilia, E. (2010). Teaching writing: Developing critical leamers. Bandung: Rizki Press.

Evans, G. and Guba, P. (2002). How to write a better thesis. melbourne: Melbourne UniversityPress.

Gay, L.R. (2009). Educational research: Competencies for analysis and application. New Jersey: Pearson Education.
Gerot, Linda, and Wignell, Peter. (1994). Making sense of functional grammar. Sydney: Antipodean Educational Enterprises.

Guion, A, Lisa. (2012). "Triangulation: Establising the validity of qualitative studies. University of Florida.

Halliday, M. and Hasan, R. (1976). Cohesion in english. London: Longman Group.

Halliday, M.A.K. (1994). An introduction to functional grammar.London; Edward Amold Ltd.

Halliday, M.A.K. (2001). Literacy and linguistics: Relationships between spoken and written language. London: Longman Group.

Halliday, M. and Mathiessen, M.I.M. (2004). Introduction to functional grammar (3rd ed). Oxford: Oxford University Press.

Jordan, R.R. (1997). English for academic purposes: A guide and resource book for teachers. Cambridge: Cambridge University Press.

Joseph, L. Nancy. (1999). Research writing using traditional and electronic sources. New Jersey: Prentice Hall.

Lawrence A. Palinkas. (2003). Purposeful sampling for qualitative data collection and analysis in mixed method implementation research. New York : Springer Science Media.

Marfuaty, A, Fitria and Wahyudi, Ribut. (2015). An analysis of thematic progression pattems: Opinion section texts of The Jakarta Post. International Journal of Language Studies 9(3), pp 109-130.

Martin, JR, MIM Christian, Painter Clare. (1997). Working with functional grammar. New York: Amold.

McHugh,M. Interrater reliability: The kappa statistic. Biochemia～Medica 2012;22(3):276-82. http://dx.doi.org/10.11613/BM.2012.031.

McCarthy, M.(1990). Issues in applied linguistics. Cambridge. Cambridge University Press. 
Miles,Matthew. (1990). Qualitative data analysis. an expended sourcebook (2ndEdition). Califomia.

Paltridge, B. (2007). Thesis and dissertation writing in a second language. London: Routledge.

Schleppegrell, M. J. (2004). The language of schooling: A functional linguistics perspective. New Jersey: Lawrence Erbaum.

Schleppegrell, M. J. 2009. Grammar for generation 1.5.: A focus on meaning. In $\mathrm{M}$. Roberage, $\mathrm{M}$. Siegal, \& L. Harklau (Eds.), Generation 1.5 in college composition: Teaching academic writing to U.S.educated leamers of ESL (pp. 221-234). New York: Routledge.

Stemler. (2001). An overview of content analysis. Wesleyan University.
Swales, John M. (1990). Genre analysis: English in academic and research settings. Cambridge: Cambridge University Press.

Thompson, G. (2004). Introducing functional grammar. New York: Oxford University Press.

Todd, R.W., Khongput, S., and Darawangsa, P. 2007. Coherence, cohesion, and comments on students' academic essays. assessing writing 12. 10-25. www.sciencedirect.com

Vande Kopple, W. J. 1991. Themes, thematic progressions, and some implications for understanding discourse. Written Communication,8(3), 311-347.doi:10.1177/ 0741088391008003002. 